\title{
Study of Fashion Accessories Design Based on 3D Printing Technology
}

\author{
Siyu CHEN, Huanyun WEI, Li ZHOU* \\ College of Textiles and Garments, Southwest University, Chongqing, China \\ DOI: $10.15221 / 17.084 \quad$ http://dx.doi.org/10.15221/17.084
}

\begin{abstract}
This paper seeks to provide stylish designs of garment accessories with a kind of 3D printing technology data resource library on the basis of categorization and analysis of manufacturing principles and material properties of 3D printing technology. Styling for garment accessories includes internal styling and external styling. Through analyzing roles that 3D printing plays in spatial relations construction of garment accessories and in realizing these roles through utilizing internal processes and materials, 3D printing's functions in constructing the internal styling of garment accessories are highlighted; through analyzing its applications in functional additions and styling of garment accessories, 3D printing's applications in external styling of garment accessories are also reflected.
\end{abstract}

Keywords: 3D printing technology; Costume accessories design; Costume accessories modeling

\section{Background of the research}

Costume accessories are all decoration and ornament for people besides clothes, including hair, makeup, jewelry, hats, glasses, shoes, bags, towels, umbrellas, gloves, fans, wigs, tattoos, etc. In order to meet the appreciation of the beauty needs of the wearer, modeling is to create a three-dimensional image of costume accessories and to display the decorative features with material characteristics and technological means by costume accessories, and display the decorative features with material characteristics and technological means by clothing accessories in order to meet the appreciation of the beauty needs of the wearer. The costume accessories model is divided into the inner space molding and exterior space modeling.

The interior space of costume accessories refers to the space produced between costume accessories and human body, as well as the space formed by the internal composition and integration of costume accessories. The interior space modeling of costume accessories is realized by molding method and making technology. At the same time, costume accessories of different materials will also have the impact of costume interior space modeling. The interior space modeling of costume accessories affects the exterior modeling features of costume accessories, and sometimes it meets the needs of the function.

The exterior space modeling of costume accessories refers to the costume accessories surface and the external environment of the physical characteristics of the transfer, which occupies a certain amount of environmental space. The exterior space modeling of costume accessories is affected by the interior space modeling of costume accessories.

The special relationship between clothing and accessories, surface characteristics of clothing accessories, decorative styling on the surface of clothing accessories, the change of the clothing accessories space and the increase or decrease of space are the elements that the composition of the external space form of the garment, and these elements needs through the use of different materials with a variety of technical means and modeling technique can be realized. As for the construction of the interior space of costume accessories, 3D printing has the unique advantages of giving full play to the designer's thought and designing the full presentation of its design. The modeling of the internal space of costume accessories sex is mainly the emphasis on human body shape and decorate, and is in the costume accessories based on functional space to supplement and extension, indirectly expressed a cultural life and aesthetic characteristics of The Times.

* Fund project: This research is supported by "Fundamental Research Funds for the Central Universities (XDJK2016C100)".

About the Author: CHEN Siyu, female, postgraduate, the main research direction is the digital clothing design. Communication author: ZHOU Li, E-mail: mydtcazz@126.com. 
The high heels, for example, had been a significant element from Chinese Ming dynasty in the 15th century to the Eighteenth-century .As a unique form in the history of costume accessories, and it clearly expresses the interior space modeling of costume accessories. By scanning and design modeling and now we can use 3D printing, it is easier and faster to produce high heels and to make a modern interpretation and innovation, which is a result of (3D printing can be convenient to handle complex modeling form typical embodiment, as shown in figure 1.
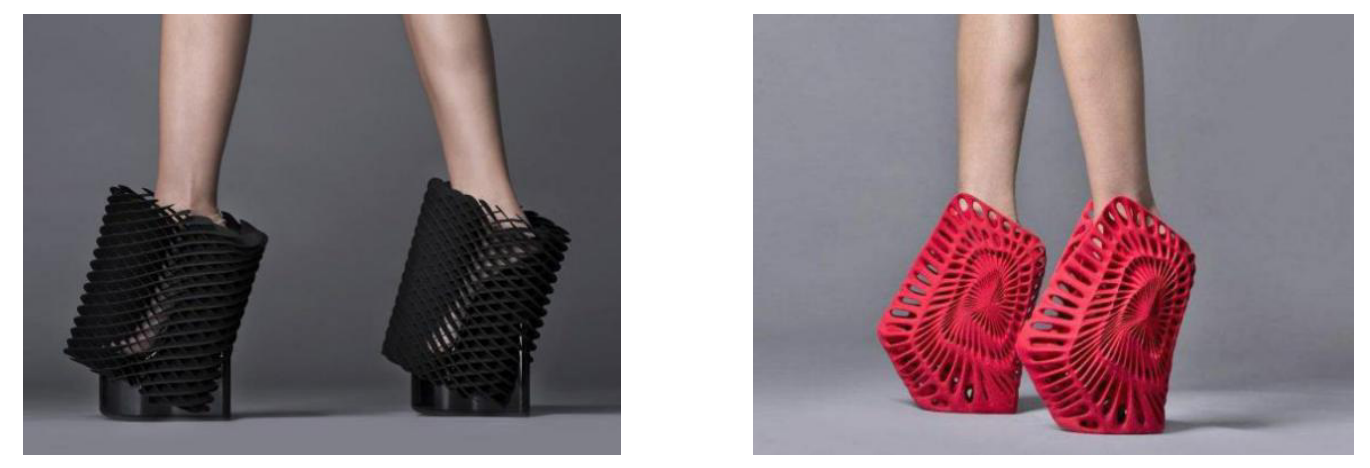

Figure 1: 3D printing high heels

The emergence of 3D printing technology has brought about a revolutionary innovation for the design and production of the interior space of costume accessories. First of all, various types of printing materials replace the traditional molding materials, and have achieved better modeling and using effect. In a jewelry store - 3D printing design MYBF, which belongs to Orlando. It is light and strong nylon that is used for printed materials to create jewelry. It reinterprets the traditional images of jewelry, and so that the design of accessories unique, as shown in figure 2.

The innovation of 3D printing technology in craft modeling: modeling process is not affected by the material resistance to curvature and connectivity constraints, and it can be made into any shape; the molding process does not need to be modeling fixed and association through the connector, therefore, the stability and industrial strength of the model are improved; the styling products is reduced by the transformation of the material and the printing parameter settings; significantly reduce the difficulty of manufacturing process the accessories, and saving the process of the product time-consuming.

At the same time, 3D printing technology continues to update and develop, and different printing process and printing materials for the design of costume accessories to bring a new experience. International sporting goods giant Nike using 3D printing technology to create a Rebento sports backpack, this backpack with advanced manufacturing technology and the integration of traditional technology. It has become a bold attempt of Nike by creating the skeleton structure and high-quality leather fusion through the 3D printer technology, as shown in figure 3.

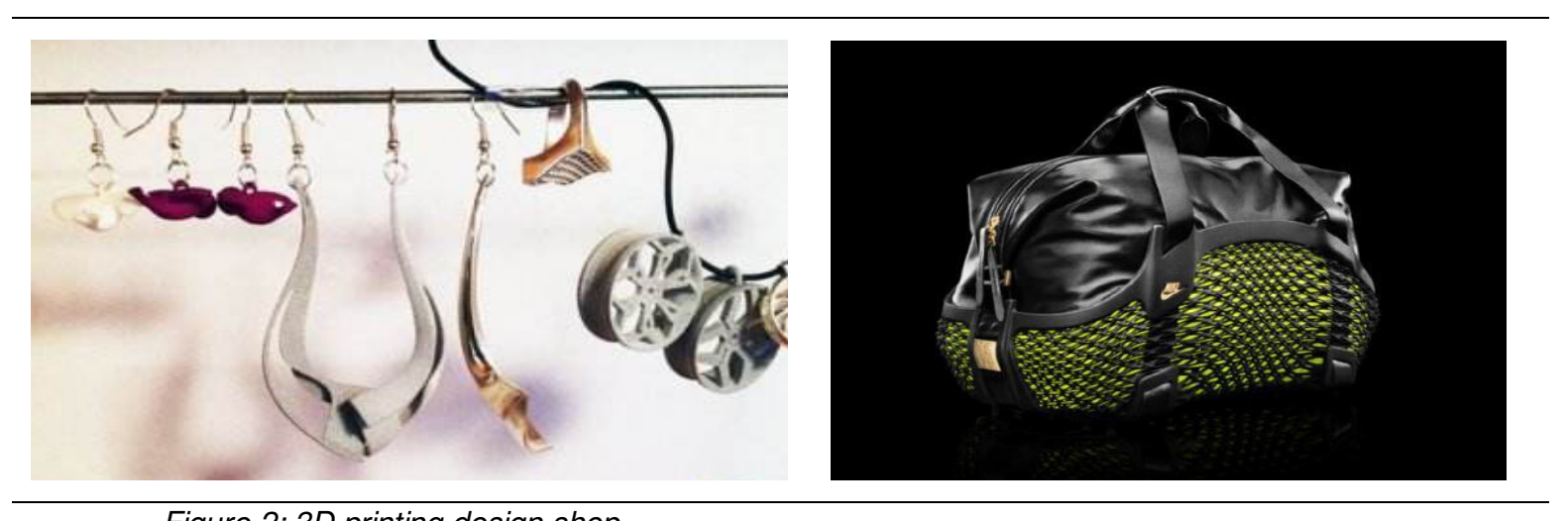

Figure 2: $3 D$ printing design shop MYBF $3 D$ printing jewelry

Figure 3: 3D printing Rebento sports backpack 


\section{Process of the research}

\subsection{Experimental methods and experimental materials}

The object of this paper is the castle backpack, opus inspired by the castle. The writer will be a symbol of stability of the elements of the castle into the design of accessories, make its practicality and adornment sex fully union.

\subsubsection{Experimental methods}

This experiment firstly analyzed the form of the castle and measured the model of the structure of the data through the castle modeling ratio, and carried out research and analysis from the backpack castle modeling of internal styling and external modeling to. Because the complex structure of castle sculpts, firstly, it is divided into several geometric shapes to model, and then 3D printing and backpack production, and general research way is shown in figure 4 .

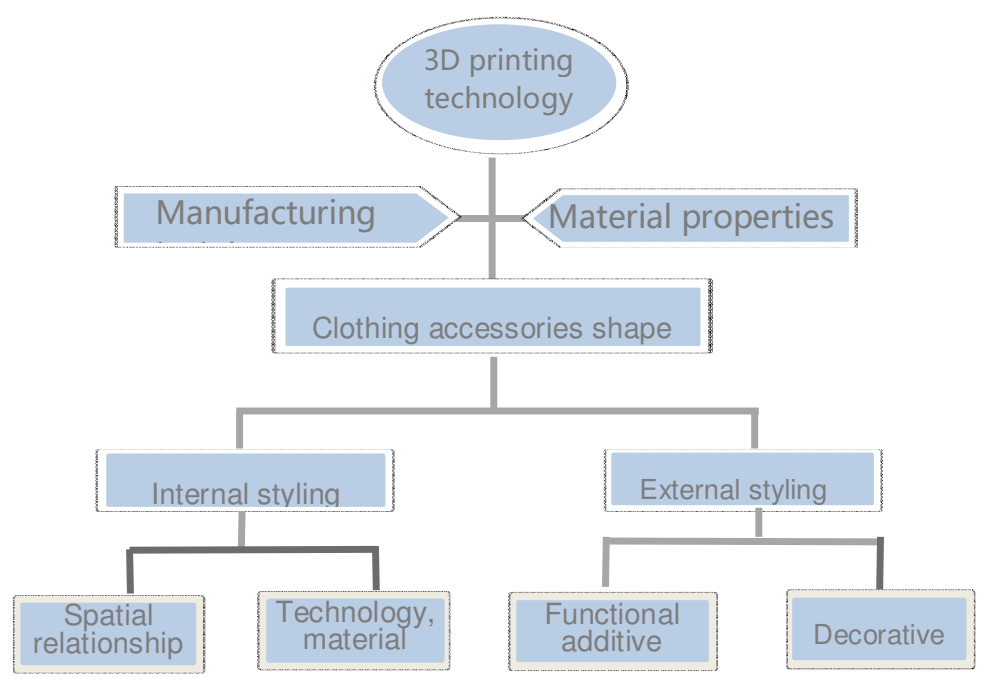

Figure 4: research ideas

\subsubsection{Experimental materials}

Survey object: castle building in Western Europe

Experimental software: 3DMAX software

Instruments and equipment: MakerPi M2030, positioning accuracy of the printer: the XY axis is 0.0128 $\mathrm{mm}$, and the z-axis is $0.0025 \mathrm{~mm}$; the printing accuracy is plus or minus $0.1-0.3 \mathrm{~mm}$; the forming principle is the melting fiber and the melting deposit.

Experimental materials: the printed material is ABS (acrylonitrile-butadiene-styrene copolymer), golden silk pale grey fabric.

\subsection{Experimental processes}

This article selected 3DMAX software to show on 3D of Castle's sculpts. In the process of modeling, and castle that complex sculpt structure can be divided into a few simple modules for modeling. It can be divided to the main structure, auxiliary structure and decoration structure, the internal structure of this work can further determine through analysis of those three parts above, three-dimensional model manufacturing is made through the entire three-dimensional structure and the establishment of internal structure, as shown in figure 5 . 


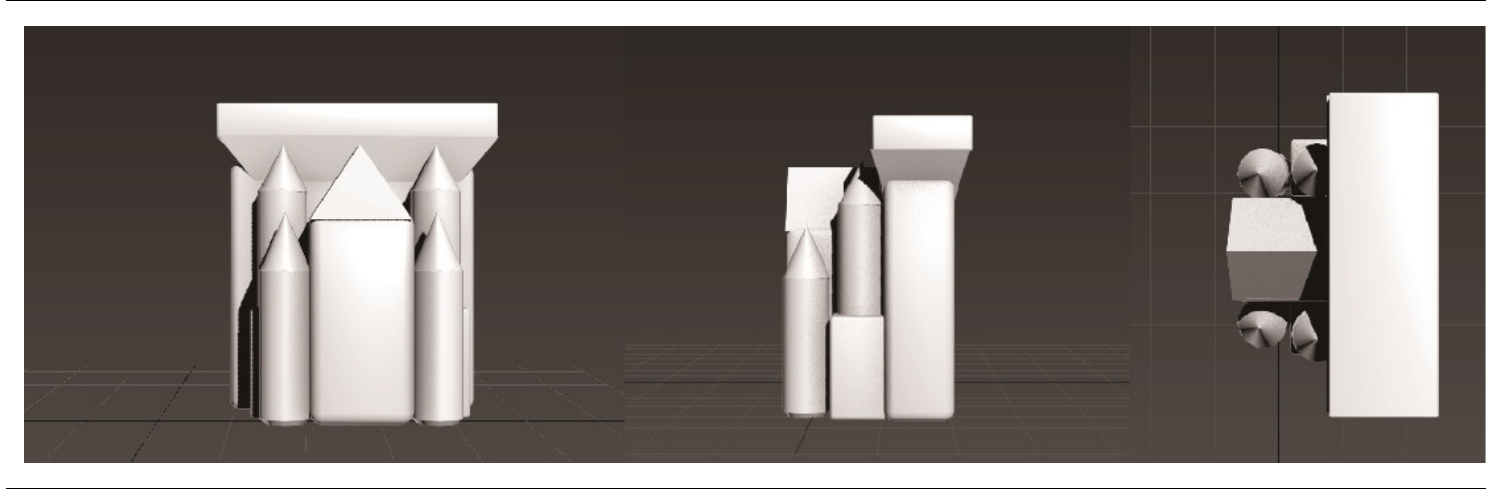

Figure 5: 3D model of castle modeling

Test for the sealing ability of the model should be done after the three-dimensional modeling is finished. The model needs to be a closed entity, so that the thickness can be achieved. After being successfully tested, the modeling will be put into the 3D printing software to have a hierarchical print preview and final adjustment to the size and details. The maximum size of the object model is based on the maximum size that can be printed by the 3D printer. When the model exceeds the maximum size of the 3D printer, the model cannot be printed out completely. As the castle model have need to be assembled, so we need to reserve a width of $0.8 \mathrm{~mm}$ in the place that need to be closely connected and a width of $1.5 \mathrm{~mm}$ for the loose place.

Then we will select print density and finally print the model in 3D. The shape of the castle is printed by 3D printing technology, which is made of light grey metal fabric. Finally, decorate with silver zippers and ribbons.

\subsection{Experimental results}

The castle backpack produced by the combination of the skeleton structure and the fabric made by the 3D printer technology, the spatial sense of its internal styling and craftsmanship, and the combination of the decorative and functional aspects of the exterior styling. Make the entire design stereo modeling perfect presentation, design more atmosphere, as shown in figure 6.
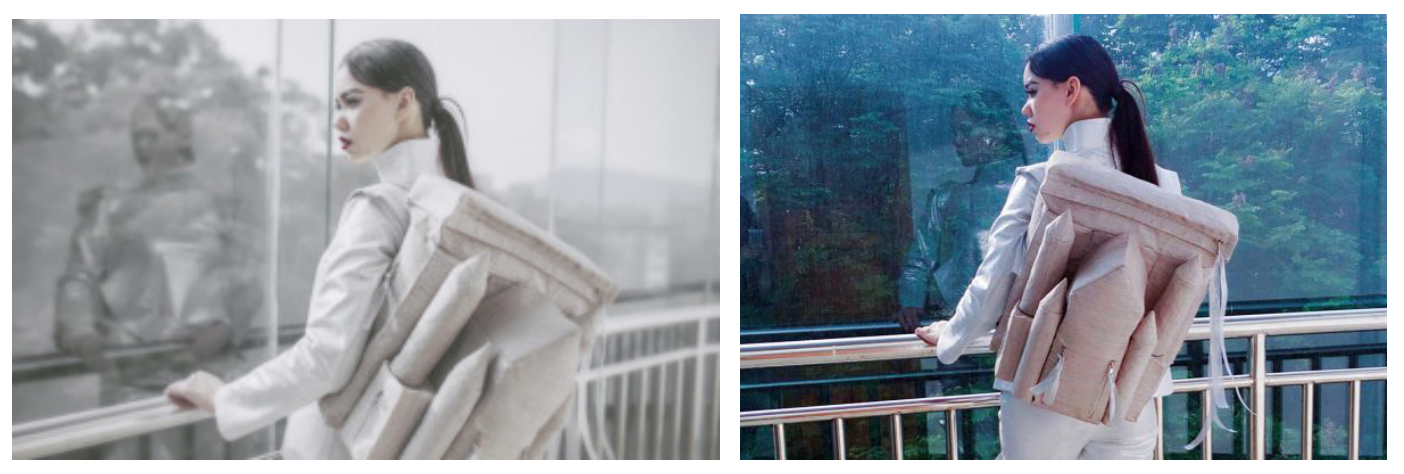

Figure 6: work display

In backpack design, the use of 3D printing technology reduces the difficulty in making and brings a styling better than the hand-carved or fabric-stitched styling, and the work is more elaborate, and the time is shorter and the success rate is higher. The advantages shown in these experiments can be seen in every design process, and 3D printing technology is becoming more and more mature, it can be obtained through 3D printing technology for the design of complex and changeable costume accessories. 
In the current costume accessories industry, once owning 3D printing technology, various enterprises and design agencies can constantly adjust and accurately achieve the design concept of costume accessories, and reduces the cost of sample production in this process. The 3D printing technology also helps greatly shorten the design cycle of costume accessories, bringing about more diverse and bold design so that the enterprises can introduce new products constantly quickly.

\subsection{Prospect}

The market of costume accessories is gradually expanding, and the design of costume accessories is slowly becoming the important competition factor of innovative ideas and advanced technologies. Such competition promotes the advancement and innovation of costume accessories design industry. With the development of 3D technology, 3D printing technology will become an advanced application method with full-blown design system.

However, 3D printing technology needs to solve the material's tensile properties and the thickness of molded products and so on in the application of costume accessories design area. We believe that these problems will be solved, and there will be more innovative technology converts to manufacturing capacity, and we believe it will show some unique advantages in costume accessories design field, and what's more, to achieve the designer's whimsy, to bring unlimited possibilities to the design industry of costume accessories will be imaginable in the near future.

\section{References:}

[1] WU Jing-fang. Fashion Accessory[M]. Shanghai: Donghua University Press, 2004

[2] WANG Xiu-chun, WEI Jun, YI Xi-bin, ZHANG Jing, SHANG Kai, WANG Qian .3D Printing Technology and Printing Material Adaptability[J]. Information Technology and Information Technology, 2014(4):90-92.

[3] WU Huan-yu.3D Printing Three-Dimensional Creation Via Intelligent Digitization. Publishing House of Electronics Industry. 2014

[4] WU Huan-yu. 3D Digitization and 3D Printing: Using "Virtual" to Recreate "Reality" (Part I)

[5] GAO Yang. 3D Printing Technology Application In Product Design Research [D]. Beijing University of Technology, 2012

[6] FANG Ju-qiang. Research on the Mechanism of 3D Printing Rapid Prototyping and Machining Quality Control Technology[D]. Northeastern University, 2010.

[7] LI Gang. Try to Subvert the First Test of the Personal 3D Printer of the Technology Revolution (7). [EB / OL]. 2012.

[8] LI Qing, WU Ya-lan, Application of RPM in Modern Manufacturing [J]. Industrial \& Science Tribune, 2014(24):68-68.

[9] LIU Shu-hua. Technology and Application of Rapidly Prototyping Manufacturing[J]. New Technology \& New Process, 2000(9):19-21.

[10] LUO Jing, YANG Jixin, WANG Xu. Three Dimensional Human Body Modeling Technology [J]. Journal of Dalian Polytechnic University, 2004, (6).

[11] JIN Ling. Application and Development of Apparel Accessories[J]. Light Industry Science and Technology, 2012(4):110-111.

[12] LIN Shan, CHEN Tie. Introduction to 3D Printing Technology. Rubber \& Plastics Resources Utilization. 2014(05):27-32.

[13] DENG Long-hui,LIU Xiao-jing. Analysis of 3D Printing Technology and Its Development in China [J]. Telecom World, 2014(7):125-126.

[14] Hod Lipson, Melba Kurman. 3D Printing: From Dream to Reality, China Citic Press, 2013. 